\title{
Isotope Measurement of Uranium at Ultratrace Levels Using Multicollector Inductively Coupled Plasma Mass Spectrometry
}

\author{
Seong Y. Oh, Seon A. Lee, Jong-ho Park, Myungho Lee, and Kyuseok Song* \\ Nuclear Chemistry Research Division, Korea Atomic Energy Research Institute, Daedukdaero 989-111, Yuseong-gu, Dae- \\ jeon 305-353, Korea
}

Received May 23, 2012; Revised June 20, 2012; Accepted June 20, 2012

First published on the web June 28, 2012; DOI: 10.5478/MSL.2012.3.2.54

\begin{abstract}
Mass spectrometric analysis was carried out using multicollector inductively coupled plasma mass spectrometry (MC-ICP-MS) for the precise and accurate determination of the isotope ratios of ultratrace levels of uranium dissolved in 3\% $\mathrm{HNO}_{3}$. We used the certified reference material (CRM) 112-A at a trace level of $100 \mathrm{pg} / \mathrm{mL}$ for the uranium isotopic measurement. Multiple collectors were utilized for the simultaneous measurement of uranium isotopes to reduce the signal uncertainty due to variations in the ion beam intensity over time. Mass bias correction was applied to the measured $U$ isotopes to improve the precision and accuracy. Furthermore, elemental standard solution with certified values of platinum, iridium, gold, and thallium dissolved in $3 \% \mathrm{HNO}_{3}$ were analyzed to investigate the formation rates of the polyatomic ions of $\mathrm{Ir}^{40} \mathrm{Ar}^{+}, \mathrm{Pt}^{40} \mathrm{Ar}^{+}, \mathrm{Tl}^{40} \mathrm{Ar}^{+}$, $\mathrm{Au}^{40} \mathrm{Ar}^{+}$for the concentration range of $50-400 \mathrm{pg} / \mathrm{mL}$. Those polyatomic ions have mass-to-charge ratios in the $230-245 \mathrm{~m} / \mathrm{z}$ region that it would contribute to the increase of background intensity of uranium, thorium, plutonium, and americium isotopes. The effect of the polyatomic ion interference on uranium isotope measurement has been estimated.
\end{abstract}

Key words: ICP-MS, Multicollector, Isotope ratio, Uranium, Trace analysis

\section{Introduction}

Over the past few decades, inductively coupled plasma mass spectrometry (ICP-MS) has been increasingly used for ultratrace elemental analysis owing to its advanced capabilities such as high sensitivity and short measuring time. ${ }^{1-3}$ ICP-MS is superior to thermal ionization mass spectrometry (TIMS) in that it provides higher ionization efficiencies for a given sample size; this allows ICP-MS tools to be used widely for uranium(U) isotope ratio measurements at ultratrace analyte levels. ${ }^{4,5}$ The ICP-MS technique is based on the concept that plasma ions, which indicate the presence of an analyte in a sample, are driven by intense electromagnetic fields, and are then directed toward their own intrinsic paths by electric and magnetic sector analyzers. ${ }^{6,7}$ The ion currents measured by ion collector systems provide valuable information on the isotopic compositions in a sample solution. For ultratrace levels of the analytes of interest, the simultaneous measurement of different isotopes with a multicollector (MC) system is preferable to avoid the uncertainty caused by fluctuation of the ion beam intensity over time. ${ }^{5,8}$ It is due to the fact that the variations in signal intensity during the measurement period have an almost equal impact on the

*Reprint requests to Dr. Kyuseok Song

E-mail: sks@kaeri.re.kr entire detector. Previous analytical studies demonstrated that MC-ICP-MS is a convenient and accurate approach for measuring $\mathrm{U}$ isotope ratios at ultratrace levels of analyte. ${ }^{7,9}$ However, the mass bias effect, in which the transmission efficiencies of the ion beam depend on the ion's mass, poses a challenge to an accurate measurement of ion currents for the analytes of interest. ${ }^{4}$ Hence, mass bias correction is necessary to accurately determine the isotope ratios of a sample. The matrix elements in plasma are susceptible to a combination with the most abundant argon and atmospheric gases, which results in the production of polyatomic ions such as ${ }^{195} \mathrm{Pt}^{40} \mathrm{Ar}^{+},{ }^{198} \mathrm{Pt}^{40} \mathrm{Ar}^{+},{ }^{193} \mathrm{Ir}^{40} \mathrm{Ar}^{+}$, ${ }^{202} \mathrm{Hg}^{40} \mathrm{Ar}^{+},{ }^{238} \mathrm{U}^{1} \mathrm{H}^{+}$, and ${ }^{207} \mathrm{~Pb}^{16} \mathrm{O}_{2}^{+}$. The interference effect due to these polyatomic ions affects the precision and accuracy of isotopic measurements. ${ }^{10}$ The polyatomic ions of $\mathrm{Ir}^{40} \mathrm{Ar}^{+}, \mathrm{Pt}^{40} \mathrm{Ar}^{+}, \mathrm{Tl}^{40} \mathrm{Ar}^{+}, \mathrm{Au}^{40} \mathrm{Ar}^{+}$whose mass-to-charge ratios are around the $230-245 \mathrm{~m} / \mathrm{z}$ region would contribute to the increase in background intensity of actinide isotopes such as ${ }^{233} \mathrm{U},{ }^{236} \mathrm{U},{ }^{243} \mathrm{Am}$, and ${ }^{231} \mathrm{Th}$. Consequently, it might cause the overesti- mation of these actinide isotopes at ultratrace levels.

In this study, the $\mathrm{U}$ isotope ratio was measured using CRM 112-A at a trace level of $100 \mathrm{pg} / \mathrm{mL}$ obtained from the US Department of Energy, New Brunswick. The standard reference material (SRM) U-005 was used as a bracketing standard for mass bias correction of the measured $\mathrm{U}$ isotope ratios from CRM 112-A. In addition, the production rates of the polyatomic ions were investigated 
using elemental standard solutions of $\mathrm{Ir}, \mathrm{Au}, \mathrm{Pt}$, and $\mathrm{Tl}$ diluted in $3 \% \mathrm{HNO}_{3}$.

\section{Experiment}

An MC-ICP-MS (NEPTUNE Plus, Thermo Scientific Inc.) instrument equipped with multi-collectors, an array of moveable detectors with nine Faraday cups, and five multiion counters, was used to measure the ultratrace $U$ isotopes. The ion counters consist of three secondary electron multipliers (SEMs) and two compact discrete dynodes (CDDs). The ion counters were positioned on the low mass side. We employed the ion counters for measuring minor isotopes ${ }^{234} \mathrm{U}$ and ${ }^{235} \mathrm{U}$ of CRM 112-A. The instrument was operated in low-resolution mode $(\mathrm{m} / \Delta \mathrm{m}=400)$. The sample introduction system (CETAC Aridus II) on the ICP-MS instrument contained a membrane desolvator and a spray chamber coupled with a perfluoroalkoxy (PFA) nebulizer with a nominal uptake rate of $50 \mu \mathrm{L} / \mathrm{min}$. The nebulized aerosol of argon and a sample diluted with $3 \% \mathrm{HNO}_{3}$ were fed continuously into the spray chamber heated at $110{ }^{\circ} \mathrm{C}$, which maintained the sample in the vapor phase. The membrane desolvator was operated at $160^{\circ} \mathrm{C}$. The argon gas swept the solvent vapor into the porous wall of the heated membrane desolvator. Consequently, the sample aerosols had reduced the amount of solvent vapor, and they were aspirated into the argon plasma. This resulted in the enhancement of the sensitivity of the analyte isotopes. The argon plasma was driven into the argon gas flow by intense
Table 1. Operating parameters for MC-ICP-MS

\begin{tabular}{cc}
\hline \hline Extraction Voltage $(\mathrm{V})$ & -2000 \\
RF power $(\mathrm{W})$ & 1200 \\
Cool gas $(\mathrm{L} / \mathrm{min})$ & 15 \\
Auxiliary gas $(\mathrm{L} / \mathrm{min})$ & $0.4-0.8$ \\
Sample gas $(\mathrm{L} / \mathrm{min})$ & $0.4-0.7$ \\
Aridus sweep gas $(\mathrm{L} / \mathrm{min})$ & $3-4$ \\
Aridus $\mathrm{N}_{2}(\mathrm{~mL} / \mathrm{min})$ & 8 \\
Nebulizer $(\mu \mathrm{L} / \mathrm{min})$ & 50 \\
\hline
\end{tabular}

radio-frequency fields (27.12 $\mathrm{MHz})$. We used high-purity nitric acid (Merck, Ltd.) and Milli-Q de-ionized water $(\sim 18$ $\mathrm{M} \Omega \cdot \mathrm{cm})$ to dilute the reagents in our experiments. The background intensities of $3 \% \mathrm{HNO}_{3}$ measured by the ion counter were typically ${ }^{233} \mathrm{U},{ }^{236} \mathrm{U},{ }^{234} \mathrm{U}<1 \mathrm{cps},{ }^{235} \mathrm{U}<50 \mathrm{cps}$, and ${ }^{238} \mathrm{U}<3000 \mathrm{cps}$. The tuning windows for controlling the torch position, the amount of instrumental gas, and the ion lenses were routinely adjusted to optimize the sensitivity and stabilize the ion beam intensity. We used the SRM U-005 solution ( $5 \mathrm{pg} / \mathrm{mL})$ and collected its ${ }^{238} \mathrm{U}$ beam intensity in a Faraday cup to tune the MC-ICP-MS system. The typical operating conditions are given in Table 1.

\section{Results and Discussion}

\section{Polyatomic ion interference effect}

Polyatomic ions were measured using elemental standard
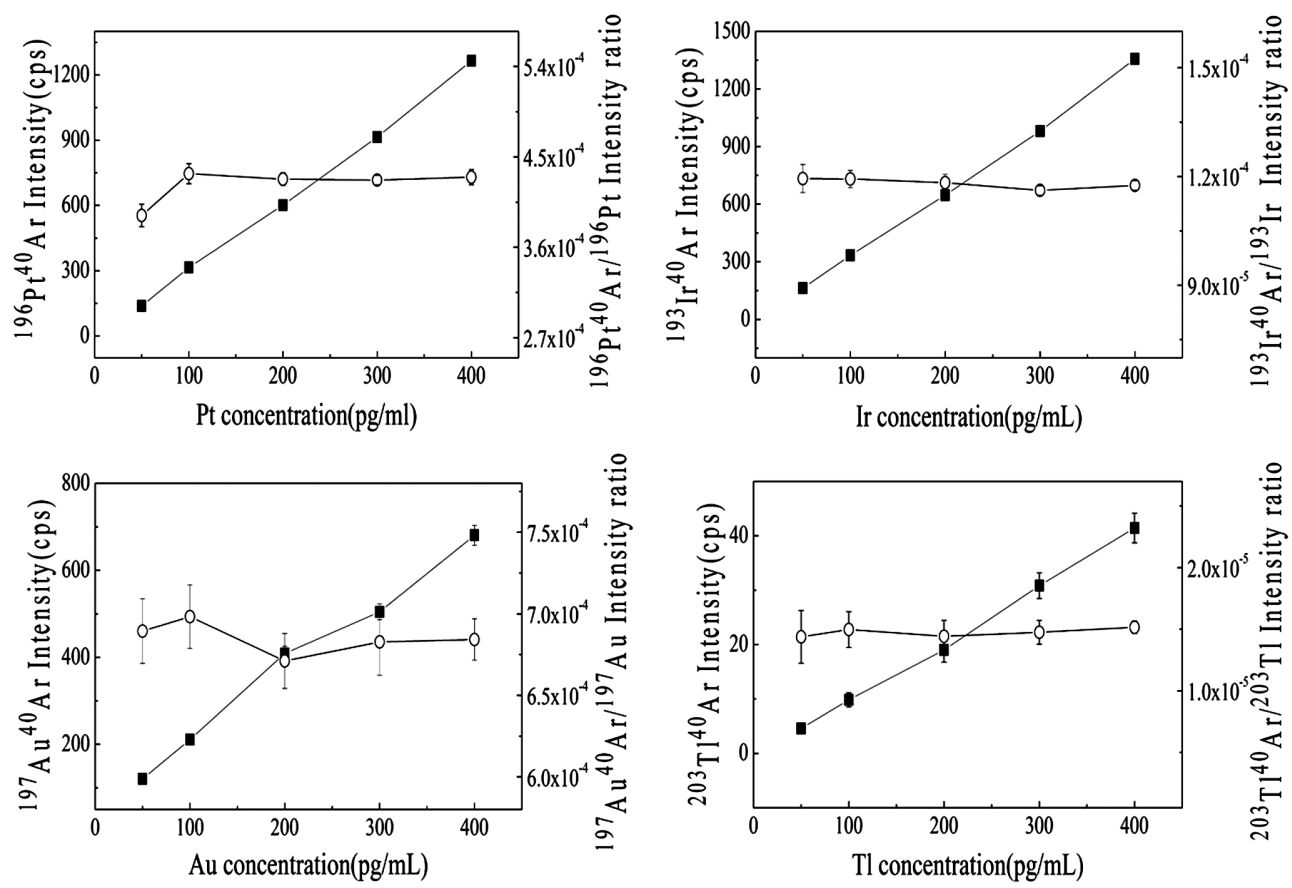

Figure 1. Squares represent the calibration curves of the poly- atomic ions ${ }^{196} \mathrm{Pt}^{40} \mathrm{Ar},{ }^{193} \mathrm{Ir}^{40} \mathrm{Ar},{ }^{197} \mathrm{Au}^{40} \mathrm{Ar}$, and ${ }^{205} \mathrm{Tl}{ }^{40} \mathrm{Ar}$ in the concentration range $50-400 \mathrm{pg} / \mathrm{mL}$. Open circles represent ${ }^{196} \mathrm{Pt}{ }^{40} \mathrm{Ar} /{ }^{196} \mathrm{Pt},{ }^{193} \mathrm{Ir}{ }^{40} \mathrm{Ar} /{ }^{193} \mathrm{Ir},{ }^{197} \mathrm{Au}{ }^{40} \mathrm{Ar} /{ }^{197} \mathrm{Au}$, and ${ }^{203} \mathrm{Tl}{ }^{40} \mathrm{Ar} /{ }^{203} \mathrm{Tl}$ ratios. 
solutions of $\mathrm{Ir}, \mathrm{Au}, \mathrm{Pt}$, and $\mathrm{Tl}$ diluted in $3 \% \mathrm{HNO}_{3}$ (Anapex Co., Ltd.) to investigate the polyatomic ions that might affect the accuracy and precision of the isotopic measurement of actinide elements. The polyatomic interference arising from the cluster ions generated in the plasma source depends on the sample composition. Heavy matrix elements ( $\mathrm{Ir}, \mathrm{Au}, \mathrm{Pt}$, and $\mathrm{Tl})$ combined with the most abundant atoms $\left({ }^{40} \mathrm{Ar}\right)$ in the plasma have mass-to-charge ratios in the 230-245 m/z region. ${ }^{11,12}$ Consequently, the $\mathrm{Ir}^{40} \mathrm{Ar}, \mathrm{Pt}^{40} \mathrm{Ar}, \mathrm{Au}^{40} \mathrm{Ar}$, and $\mathrm{Tl}^{40} \mathrm{Ar}$ polyatomic ions produced in the plasma might interfere with the measurement of the actinide elements (U, $\mathrm{Pu}, \mathrm{Am}$, and $\mathrm{Th})$. Figure 1 shows the intensities and intensity ratios of the ${ }^{196} \mathrm{Pt}^{40} \mathrm{Ar},{ }^{193} \mathrm{Ir}^{40} \mathrm{Ar},{ }^{197} \mathrm{Au}^{40} \mathrm{Ar}$ and ${ }^{203} \mathrm{Tl}^{40} \mathrm{Ar}$ polyatomic ions for the concentration range 50 $400 \mathrm{pg} / \mathrm{mL}$. The signal intensities of the polyatomic ions grow steadily with the increase of the matrix (Ir, Au, Pt, and $\mathrm{Tl}$ ) concentration. In contrast, the intensity ratios of $\mathrm{Ir}^{40} \mathrm{Ar} /$ Ir, $\mathrm{Pt}^{40} \mathrm{Ar} / \mathrm{Pt}, \quad \mathrm{Tl}^{40} \mathrm{Ar} / \mathrm{Tl}$ and $\mathrm{Au}^{40} \mathrm{Ar} / \mathrm{Au}$ tend to be independent of the matrix element concentration. $\mathrm{Pt}^{40} \mathrm{Ar}$ interferes with ${ }^{234} \mathrm{U},{ }^{235} \mathrm{U},{ }^{236} \mathrm{U}$, and ${ }^{238} \mathrm{U}$ because Pt has isotopes with the mass numbers $194,195,196$, and $198 .^{12}$ This interference might lead to the overestimation of the amounts of these $U$ isotopes at ultratrace levels. For instance, natural $\mathrm{U}$ has no ${ }^{236} \mathrm{U}$ isotope. The signal intensity of ${ }^{196} \mathrm{Pt}^{40} \mathrm{Ar}$ and its standard deviation measured at $400 \mathrm{pg} /$ $\mathrm{mL}$ were $(1.270 \pm 0.024) \times 10^{3} \mathrm{cps}$. This corresponds to $\sim 54.5 \mathrm{fg} / \mathrm{mL}$ of ${ }^{236} \mathrm{U}$. Under our measurement conditions, the average values of intensity ratios of ${ }^{194} \mathrm{Pt}^{40} \mathrm{Ar} /{ }^{194} \mathrm{Pt}$ and ${ }^{196} \mathrm{Pt}^{40} \mathrm{Ar} /{ }^{196} \mathrm{Pt}$ in the concentration range $50-400 \mathrm{pg} / \mathrm{mL}$ were $(4.278 \pm 0.158) \times 10^{-4}$ and $(4.220 \pm 0.171) \times 10^{-4}$. Ir forms the polyatomic ions ${ }^{191} \mathrm{Ir}^{40} \mathrm{Ar}$ and ${ }^{193} \mathrm{Ir}^{40} \mathrm{Ar}$ with $\mathrm{m} / \mathrm{z}=$ 231 and 233, which might interfere with the measurements of ${ }^{231} \mathrm{Th}$ and ${ }^{233} \mathrm{U} .{ }^{12}$ The ${ }^{191} \mathrm{Ir}{ }^{40} \mathrm{Ar} /{ }^{191} \mathrm{Ir}$ and ${ }^{193} \mathrm{Ir}^{40} \mathrm{Ar} /{ }^{193} \mathrm{Ir}$ intensity ratios were $(1.186 \pm 0.022) \times 10^{-4}$ and $(1.181 \pm$ $0.013) \times 10^{-4}$. Tl exists as ${ }^{203} \mathrm{Tl}$ and ${ }^{205} \mathrm{Tl}$, and the polyatomic ions ${ }^{203} \mathrm{Tl}^{40} \mathrm{Ar}^{+}$and ${ }^{205} \mathrm{Tl}^{40} \mathrm{Ar}^{+}$have the same mass numbers as ${ }^{243} \mathrm{Am}$ and ${ }^{245} \mathrm{Am}$. The ${ }^{203} \mathrm{Tl}^{40} \mathrm{Ar}^{+} p^{203} \mathrm{Tl}$ and $\left.{ }^{205} \mathrm{Tl}^{40} \mathrm{Ar}^{+}\right|^{205}$ $\mathrm{Tl}$ intensity ratios were $(1.474 \pm 0.034) \times 10^{-5}$ and $(1.473 \pm$ $0.033) \times 10^{-5} .{ }^{197} \mathrm{Au}^{40} \mathrm{Ar}^{+}$ions are the same $\mathrm{m} / \mathrm{z}$ as ${ }^{237} \mathrm{~Np}$. We measured the signal intensity ratios of ${ }^{197} \mathrm{Au}{ }^{40} \mathrm{Ar} /{ }^{197} \mathrm{Au}$ to be $(6.981 \pm 0.099) \times 10^{-4}$. Typical environmental samples contain various matrix elements, and hence, it is necessary to evaluate the influence of the possible interfering polyatomic ions on uranium isotope measurement at ultra trace level.

\section{Uranium isotope ratio measurement}

$\mathrm{U}$ isotope ratios were measured using the standard solution (CRM 112-A, $100 \mathrm{pg} / \mathrm{mL}$ ) with the isotopic composition of natural U. Mass bias correction was carried out for the measured isotope ratios to enhance the accuracy and precision of the measurements. The mass bias effect in ICPMS is caused by instrumental mass discrimination, which is largely attributed to the mass-dependent transmission efficiencies in the plasma/vacuum interface region. ${ }^{13,14} \mathrm{We}$

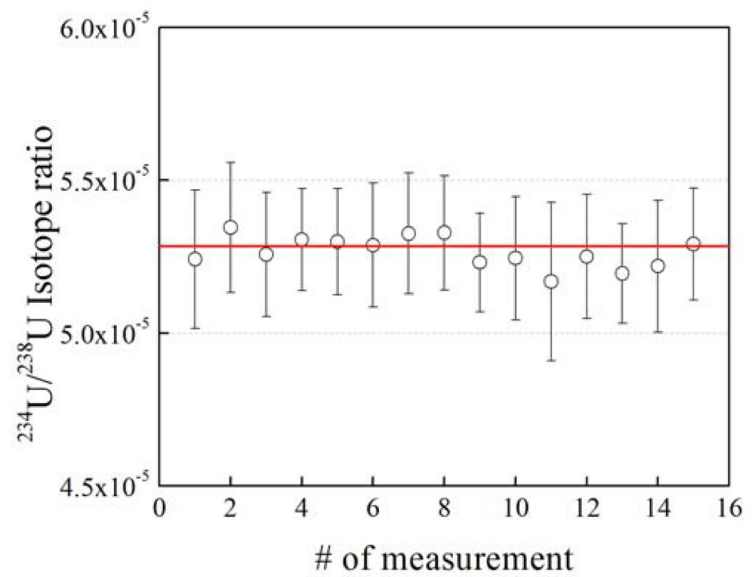

(a)

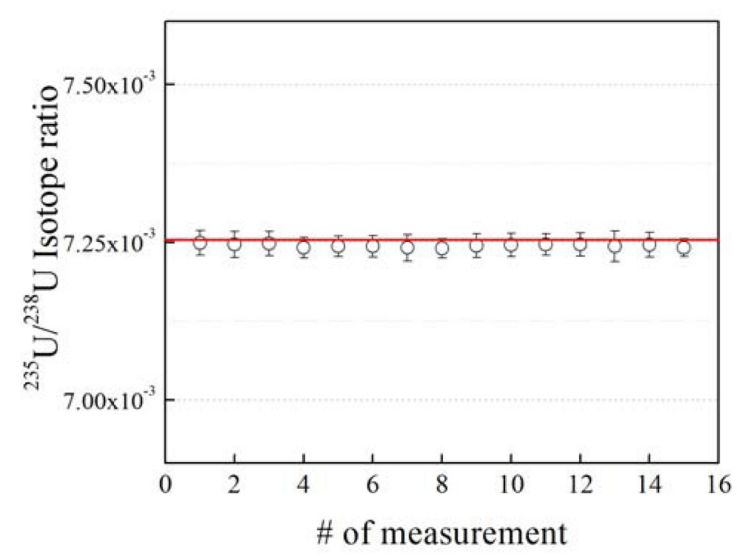

(b)

Figure 2. (a) ${ }^{234} U / /^{238} U$ and (b) ${ }^{235} U /{ }^{238} U$ isotope ratios measured for CRM 112-A. The solid lines represent the certified values of the isotope ratios ${ }^{234} \mathrm{U} /{ }^{238} \mathrm{U}$ and ${ }^{235} \mathrm{U} /{ }^{238} \mathrm{U}$.

used the following equation to correct the isotope ratios measured from CRM 112-A: $:^{4,14}$

$$
R^{c o r r}=f \bullet R^{o b s} \text { where } f=\frac{r^{\text {true }}}{r^{\text {obs }}}
$$

Here, $R^{c o r r}$ and $R^{o b s}$ are the corrected and measured isotope ratios of the CRM 112-A sample, respectively, $f$ is the mass bias factor, and $r^{\text {true }}$ and $r^{o b s}$ are the true and measured isotope ratios of the reference solution. The SRM U-005 solution, whose $U$ concentration is similar to that of CRM 112-A, was used as a reference solution to derive the mass bias factor $f$. Prior to the isotope ratio measurement, the cup configuration was spatially fitted, and the gains of the Faraday cups and ion counters were then calibrated for the simultaneous measurement of multiple $U$ isotopes. The cup configuration for the simultaneous measurement of $\mathrm{U}$ isotopes is shown in Table 2. In data acquisition, a time of 
Table 2. Cup configuration designed for the simultaneous measurement of $U$ isotopes. IC\#2 and IC\#3 refer to ion counters. L4 refers to the Faraday cup detector

\begin{tabular}{cccc}
\hline \hline Line & IC \#3 & IC \#2 & L4 \\
\hline Uranium isotope & ${ }^{234} \mathrm{U}$ & ${ }^{235} \mathrm{U}$ & ${ }^{238} \mathrm{U}$ \\
\hline
\end{tabular}

Table 3. U isotope measurement for CRM 112-A. In the "Measured" results, the average values and standard deviation of ${ }^{234} \mathrm{U} /{ }^{238} \mathrm{U}$ and ${ }^{235} \mathrm{U} /{ }^{238} \mathrm{U}$ ratios are taken from 15 measurements. The asterisk symbol $(*)$ indicates standard deviation

\begin{tabular}{ccc}
\hline \hline CRM 112-A & ${ }^{234} \mathrm{U} /{ }^{238} \mathrm{U}$ & ${ }^{235} \mathrm{U} /{ }^{238} \mathrm{U}$ \\
\hline Certified & $5.24841 \times 10^{-5}$ & $7.2543 \times 10^{-3}$ \\
Measured & $(5.26601 \pm * 0.05139) \times 10^{-5}(7.2444 \pm * 0.0026) \times 10^{-3}$ \\
\hline
\end{tabular}

$60 \mathrm{~s}$ was typically needed, as the signal became stabilized after the sample introduction. ${ }^{8}$ The integration time, i.e., the length of time used to integrate the ion current signals, was set to $4.194 \mathrm{~s}$. The idle time needed for the magnetic field and Faraday cup detectors to settle was set to $3.0 \mathrm{~s}$. Each measurement was performed over 40 acquisition cycles. For this measurement, a nebulizer with an uptake rate of $50 \mu \mathrm{L} / \mathrm{min}$ was used, and the concentration was $100 \mathrm{pg} /$ $\mathrm{mL}$. The total amount of $U$ consumed per measurement was thus deduced to be $\sim 29 \mathrm{pg}$. Figure 2 shows the corrected $U$ isotope ratios of CRM 112-A. The certified values are within the error bars of the measured isotope ratios. In the sampling sequence, 112-A and U-005 were measured in turn. The isotope ratios of 112-A were then corrected for each measurement. Table 3 presents the average values of the ${ }^{234} \mathrm{U} /{ }^{238} \mathrm{U}$ and ${ }^{235} \mathrm{U} /{ }^{238} \mathrm{U}$ ratios from 15 measurements. According to reference 16 , the expanded uncertainty values of the certified values of ${ }^{234} \mathrm{U} /{ }^{238} \mathrm{U}$ and ${ }^{235} \mathrm{U} /{ }^{238} \mathrm{U}$ in Table 3 are $8.2 \times 10^{-8}$ and $4.0 \times 10^{-6}$. The expanded uncertainty is expressed as $\mathrm{k} \cdot \mathrm{u}_{\mathrm{c}}$, where $\mathrm{k}$ is the coverage factor $(\mathrm{k}=2)$ and $\mathrm{u}_{\mathrm{c}}$ is the combined standard uncertainty. The expanded uncertainties for the measured isotope ratios were calculated according to the Joint Committee for Guides in Metrology (JCGM) Guide to the Expression of Uncertainty in Measurement. ${ }^{16}$

\section{Conclusion}

The U isotope ratio was measured using CRM 112-A at ultratrace levels, and mass bias correction was performed. Without mass bias correction, the relative errors in the measured ${ }^{234} \mathrm{U} /{ }^{238} \mathrm{U}$ and ${ }^{235} \mathrm{U} /{ }^{238} \mathrm{U}$ ratios to the certified values were $1.67 \%$ and $1.52 \%$, respectively. On the other hand, the relative errors in the measured ${ }^{234} \mathrm{U} /{ }^{238} \mathrm{U}$ and ${ }^{235} \mathrm{U} /$ ${ }^{238} \mathrm{U}$ ratios to the certified values were reduced to be $0.34 \%$ and $0.14 \%$ after mass bias correction as shown in Table 3 . Furthermore, we investigated the effect of polyatomic ions that may interfere with the $U$ isotopic measurement. Since natural $U$ contains no ${ }^{236} \mathrm{U}$ and very little of the abundant ${ }^{234} \mathrm{U}$, the polyatomic ions ${ }^{196} \mathrm{Pt}^{40} \mathrm{Ar}^{+}$and ${ }^{194} \mathrm{Pt}^{40} \mathrm{Ar}^{+}$were shown to affect the accuracy of the isotopic measurement of ultratrace levels of uranium. It is important to estimate the formation rates of those polyatomic ions with mass-tocharge ratios in the $234-238 \mathrm{~m} / \mathrm{z}$ region, which might lead to the overestimation of the amounts of the $\mathrm{U}$ isotopes.

\section{Acknowledgements}

This work was supported by the long-term nuclear research and development project form Nuclear Safety and Security Commission.

\section{References}

1. Baglan, N.; Hemet, P.; Pointurier F.; Chiappini, R. J. Radioanal. Nucl. Chem. 2004, 261, 609.

2. Jakubowski, N.; Prohaska, T.; Rottmann, L.; Vanhaecke, F. J. Anal. At. Spectrom. 2011, 26, 693.

3. Agarande M.; Benzoubir, S.; Bouisset, P.; Calmet, D. Appl. Radiat. Isot. 2001, 55, 161.

4. Hoffmann, D. L.; Prytulak, J.; Richards, D. A.; Elliott, T.; Coath, C. D.; Smart, P. L.; Scholz, D. Int. J. Mass Spectrom. 2007, 264, 97.

5. Zhang X. Z.; Esaka, F.; Esaka, K. T.; Magara, M.; Sakurai, S.; Usuda, S.; Watanabe, K. Spectrochim. Acta B 2007, 62,1130 .

6. Agarande, M.; Benzoubir, S.; Nevia-Marques, A. M.; Bouisset, P. J. Environ. Radioact. 2004, 72, 169.

7. Yang, L. Mass Spectrom. Rev. 2009, 28, 990.

8. Tayler, R. N.; Warneke, T.; Milton, J. A.; Croudace, I. W.; Warwick, P. E.; Nesbitt, R. W. J. Anal. At. Spectrom. 2003, $18,480$.

9. Hoffmann, D. L. Int. J. Mass Spectrom. 2008, 275, 75.

10. Pointurier, F.; Hemet, P.; Hubert, A. J. Anal. At. Spectrom. 2008, 23, 94

11. Kim, C. S.; Kim, C. K.; Marin, P.; Sansone, U. J. Anal. At. Spectrom. 2007, 22, 827.

12. Magara, M. et. al., J. Nucl. Sci. Technol. 2002, 39, 308.

13. Pointurier, F.; Baglan, N.; Hemet, P., Appl. Radiat. Isot. 2004, 60, 561 .

14. Albarede, F.; Telouk, P.; Blichert-Toft, J.; Agranier, A.; Nelson, B., Geochim. Cosmochim. Acta, 2004, 68, 2725.

15. Ciceri, E.; Recchia, S.; Dossi, C.; Yang, L.; Sturgeon, R. E., Talanta 2008, 74, 642.

16. New Brunswick Laboratory U.S. Department of Energy, http://www.nbl.doe.gov 